\title{
Avaliação da imunomarcação de células-tronco tumorais em carcinossarcomas mamários e carcinomas em tumores mistos em cadelas ${ }^{1}$
}

\author{
Geórgia M. Magalhães ${ }^{2 *}$, Erika M. Terra3 ${ }^{3}$, Sabryna G. Calazans², Rosemeri de 0. \\ Vasconcelos $^{3}$ e Antonio Carlos Alessi ${ }^{3}$
}

\begin{abstract}
Magalhães G.M., Terra E.M., Calazans S.G., Vasconcelos R.O. \& Alessi A.C. 2014. [Evaluation of immunostaining of tumor stem cells in mammary carcinosarcomas and carcinomas in mixed tumors in bitches.] Avaliação da imunomarcação de células-tronco tumorais em carcinossarcomas mamários e carcinomas em tumores mistos em cadelas. Pesquisa Veterinária Brasileira 34(5):455-461. Hospital Veterinário, Universidade de Franca. Dr. Armando Salles Oliveira 201, Cx. Postal 82, Parque Universitário, Franca, SP 14404-600, Brazil. E-mail: georgiamode@hotmail.com

Cancer stem cells belong to a small population of cells within the tumor with properties of self-renewal and differentiation into other cell types. In this study, the behavior of both portions, mesenchymal and epithelial, was evaluated. Six carcinosarcomas (CSs), 11 carcinomas within mixed tumors (CWMTs) grade I, 11 grade II, and 10 grade III were evaluated. In the epithelial portions of the CS and CWMTs was observed immunostaining for antibodies CD44, CD24, Oct-4 and ALDH-1. In the mesenchymal portions of the CS, in the epithelial portions of CMTs grades II and III no immunostaining for ALDH-1 was found. It was concluded that the tumor stem cells are expressed in equal proportions in the epithelial and mesenchymal portions of the CS. No immunostaining in the mesenchymal portions of well-differentiated CWMTs was seen.
\end{abstract}

INDEX TERMS: CD44, CD24, Oct-4, ALDH-1, mammary neoplasms, diseases of dogs.

RESUMO.- As células-tronco tumorais (CTTs) pertencem a uma pequena população de células dentro do tumor com propriedades de autorrenovação e diferenciação em outros tipos celulares. Neste estudo avaliou-se o comportamento tanto das porções mesenquimais quanto das epiteliais de seis carcinossarcomas (CSs), 11 carcinomas em tumores mistos (CTMs) grau I, 11 grau II e 10 grau III. Nas porções epiteliais dos CS e CTM foram observadas imunomarcações para os anticorpos CD44, CD24, Oct-4 e ALDH-1. Nas porções mesenquimais dos CS, nas porções epiteliais dos CTMs graus II e III não houve imunomarcação para o ALDH-1. Concluiu-se que as CTTs são expressas em proporções iguais tanto nas porções mesenquimais quanto nas epite-

\footnotetext{
${ }^{1}$ Recebido em 6 de setembro de 2013.

Aceito para publicação em 19 de abril de 2014 .

${ }^{2}$ Hospital Veterinário, Universidade de Franca, Rua Dr. Armando Salles Oliveira 201, Cx. Postal 82, Parque Universitário, Franca, SP 14404-600, Brasil.*Autor para correspondência: georgiamode@hotmail.com

${ }^{3}$ Departamento de Patologia Veterinária, Faculdade de Ciências Agrárias e Veterinárias , Universidade Estadual Paulista (Unesp), Via de acesso Prof. Paulo Donato Castellane s/n, Jaboticabal, SP 14884-900, Brasil.
}

liais dos CSs e ausentes nas porções mesenquimais bem diferenciadas de CTMs.

TERMOS DE INDEXAÇÃO: CD44, CD24, Oct-4, ALDH-1, neoplasias mamárias, doenças de cães.

\section{INTRODUÇÃO}

Tumores de mama são os mais frequentes em cadelas e estima-se que no Brasil a incidência de tumores malignos varia entre 68,4\% (De Nardi et al. 2002) e 73,4\% (Oliveira-Filho et al. 2010). Apesar dos enormes progressos, a oncogênese do câncer de mama continua a ser um processo de vários passos ligado a mais de uma alteração molecular (Widakowich et al. 2007). Com relação à carcinogênese mamária, estudos recentes propõem a detecção de células-tronco tumorais (CTTs) nestas neoplasias (Pang \& Argyle 2010, Michishita et al. 2011).

As células-tronco têm duas propriedades principais: a habilidade de autorrenovação, pela capacidade de divisão e formação de uma nova célula-tronco; e a diferenciação em novas células maduras em um órgão no qual residem (Al-Hajj 
\& Clarke 2004). Uma célula-tronco tecidual normal é dependente das interações com o estroma celular adjacente, caracterizando o microambiente ou nicho. Esse nicho mantém as características de autorrenovação e a identidade dessas células (Clarke et al. 2006). Da mesma forma que ocorre no tecido normal, uma CTT também interage com o estroma, sendo este indutor do crescimento do neoplasma (Blacking et al. 2007).

Devido às CTTs não poderem ser isoladas e caracterizadas como uma célula simples, marcadores específicos para superfície de CTTs foram detectados em neoplasmas mamários humanos, com marcação positiva para o CD44 e negativa ou baixa marcação para o CD24. Assim, autores (Ponti et al. 2005) criaram um modelo de estudo in vitro, constituído por uma mamosfera com culturas celulares separadas com auxílio de citometria de fluxo, para obtenção de um fenótipo CD44+/CD24- (Al-Hajj et al. 2003).

Linhagens celulares, derivadas de neoplasmas mamários caninos, que apresentam capacidade de autorrenovação (CD44+/CD24-) expressaram altos níveis de aldeído desidrogenase-1 (ALDH-1) (Michishita et al. 2012), e a expressão deste marcador em neoplasmas mamários foi relacionada com um mau prognóstico (Ginestier et al. 2007). Alguns estudos mostraram que a expressão de ALDH não se restringe apenas às células epiteliais, mas também às células do estroma (Ginestier et al. 2007, Kunju et al. 2011). Em cães, em um estudo em mamosfera, além de outros marcadores para CTTs, autores encontraram a expressão de Oct-4 (outro marcador de CTT) somente nas células da periferia da esfera; uma possível explicação seria o fato das células centrais já terem iniciado o processo de diferenciação (Ferletta et al. 2011).

Os carcinossarcomas (CSs) são tumores contendo áreas carcinomatosas e sarcomatosas. A porção epitelial pode ser caracterizada por células luminais e/ou mioepiteliais, com padrões sólido, escamoso, mucinoso e anaplásico. 0 componente mesenquimal pode ser caracterizado por áreas fibromatosas, condromatosas e osteomatosas (Misdorp et al. 1973). Esses tumores são raros na mulher e apresentam mau prognóstico quando comparados a outros tipos de carcinomas (Teixeira et al. 1998), uma vez que apresentam crescimento rápido e as metástases podem ocorrer de ambos os componentes ou só de um deles. Em cadelas, seu comportamento clínico e patológico é semelhante ao das mulheres (Misdorp et al. 1973, Cassali et al. 2011).

Os carcinomas em tumores mistos (CTMs) são muito frequentes na cadela e exibem um padrão histológico composto por porção epitelial maligna e mesenquimal bem diferenciada. Normalmente, a porção epitelial apresenta crescimento invasivo, com perda de continuidade da membrana basal e/ou células mioepiteliais associadas com invasões de agregados celulares no estroma (Cassali et al. 2011).

Neste trabalho, objetivou-se avaliar o comportamento das imunomarcações de CTTs nas porções mesenquimais e epiteliais de CSs mamários e CTMs por meio dos marcadores de CD44, CD24, Oct-4 e ALDH-1.

\section{MATERIAL E MÉTODOS}

Seis CSs mamários, 11 CTMs grau I, 11 CTMs grau II e 10 CTMs grau III foram selecionados do arquivo do Departamento de Patologia Veterinária (FCAV-UNESP Jaboticabal), incluídos em blocos de pa- rafina e as lâminas coradas com hematoxilina e eosina. Os tumores foram classificados de acordo com os critérios do Consenso em Neoplasias Mamárias (Cassali et al. 2011). Esse estudo foi aprovado pelo comitê de ética da FCAV- Unesp Jaboticabal com protocolo no. 025600-08. 0 reduzido número de carcinossarcomas deve-se à baixa casuística deste tumor na rotina do Hospital Veterinário da FCAV/Unesp Jaboticabal, onde a pesquisa foi desenvolvida.

Assim, foram comparadas as imunomarcações das porções epiteliais com as da porção mesenquimal nos CSs para os quatro anticorpos (CD44, CD24, Oct-4 e ALDH-1). Nos CTMs foram comparadas as porções epiteliais entre os graus I, II e III, uma vez que não foram observadas marcações nas porções mesenquimais. Não foram realizadas comparações entre os tipos histológicos CSs e CTMs devido ao número de amostras do CSs ser muito inferior, e também devido à ausência de marcação da porção mesenquimal dos CTMs.

Para a análise imuno-histoquímica (IHQ) foram utilizados cortes de tecidos neoplásicos mamários incluídos em parafina, para todos os anticorpos (CD44, CD24, Oct-4 e ALDH-1), de acordo com o Quadro 1. A técnica de IHQ empregada foi o método do polímero. Os cortes de tecido com $4 \mu \mathrm{m}$ foram desparafinizados, reidratados e, então, incubados por 20 minutos em uma solução a $10 \%$ de peróxido de hidrogênio (30 volumes) em metanol absoluto, para bloqueio da peroxidase endógena. Na sequência, foi realizada a recuperação antigênica pelo calor em panela de pressão (Pascal, DAKO). Apenas para o anticorpo CD24 usou-se como solução tampão Tris-EDTA, pH 9,0, de acordo com Magalhães et al. (2013), e para os demais anticorpos foi utilizado o tampão citrato pH 6,0. Após essa etapa, os cortes foram lavados por três vezes em solução tris HCL $(\mathrm{pH} 7,4)$ por 5 minutos e, a seguir, os sítios inespecíficos foram bloqueados com solução bloqueadora de reação inespecífica (protein block serum-free - DAKO ref. X0909). A seguir, os cortes foram incubados em câmara úmida com os anticorpos primários na diluição ótima (Quadro 1 ), a $4{ }^{\circ} \mathrm{C}$ por 18 horas. Apenas o anticorpo $\mathrm{CD} 44$ foi incubado a $28^{\circ} \mathrm{C}$ por uma hora. Depois os cortes foram novamente lavados em PBS, procedendo-se então a incubação com o polímero ligado a peroxidase, (kit ENVISION + Dual Link System Peroxidase ref K4061 - DAKO). Para os anticorpos CD24 e ALDH-1, o bloqueio da peroxidase endógena foi realizado após a incubação do anticorpo primário. As lâminas foram novamente lavadas, e a reação revelada pelo cromógeno diaminobenzidina (DAB - DAKO, ref. K3466). A seguir, a reação foi interrompida com a lavagem em água destilada, seguidas de contra-coloração com hematoxilina de Harris (1-2 minutos). Os cortes passaram pela bateria crescente de álcool e por xilol, foram montados com Permount (Fisher Scientific) e observados em microscopia de luz.

Para os anticorpos CD44 e CD24 foram usados como controle positivo, neoplasmas mamários humanos sabidamente marcados para estes anticorpos. Esses neoplasmas foram cedidos gentilmente pelo Departamento de Patologia da Faculdade de Medicina da USP em Ribeirão Preto - SP. A utilização do material humano foi aprovada pela Comissão de ética em pesquisa do HCRP e da FMRP/USP (processo 242/2011). Para os anticorpos ALDH-1 e

Quadro 1. Diluições, clones e procedência de anticorpos utilizados em neoplasmas mamários caninos

\begin{tabular}{lccc}
\hline \multicolumn{1}{c}{ Anticorpos } & Clones & Diluições & Procedência \\
\hline CD44, HCAM (M)* & IM7 & $1: 100$ & Santa Cruz, ref. 18849 \\
CD24 (M) & M1/69 & $1: 75$ & Santa Cruz, ref. 19651 \\
Oct-4 (P) & RbpAb & $1: 1000$ & Abcam, ref Ab19857 \\
ALDH-1 (M) & 44/ALDH & $1: 200$ & BD, ref 611194
\end{tabular}

* $\mathrm{M}=$ monoclonal, $\mathrm{P}=$ policlonal. 
Oct-4 foram usados controles positivos internos da própria lâmina, o bulbo do folículo piloso na derme.

Como controle negativo, substituiu-se o anticorpo primário por diluente de anticorpo (Antibody Diluent with Background Reducing Components, ref. S3022, DAKO) em todas as reações de IHQ. A observação das células foi feita em microscópio de luz binocular com equipamento para fotomicrografia digital (Nikon E200). Antes da contagem, foram feitas observações quanto ao tipo de células marcadas e a distribuição da marcação. Para a quantidade de células imunomarcadas foram aleatoriamente selecionados quatro campos por corte e foi contado um total de 100 células entre as marcadas e as não marcadas, utilizando-se objetiva de 40x. Os resultados foram expressos em porcentagem de células marcadas. Nos CSs foram contadas tanto as células epiteliais como as mesenquimais neoplásicas.

Nos CSs, as análises estatísticas foram conduzidas utilizando o programa computacional Graphpad Prisma (versão 4.0, 2003), com o teste de Mann Whitney $(\mathrm{p}<0,05)$. Nos CTMs foi utilizado o teste Kruskal-Wallis, seguido do teste de comparações múltipla de Dunn's, considerando significativo quando $\mathrm{p}<0,05$.

\section{RESULTADOS}

Para o anticorpo CD44 a imunomarcação ocorreu em membrana plasmática, em forte intensidade (Fig. 1A e 1B). Esta marcação foi confirmada pelo uso de uma neoplasia mamária humana sabidamente marcada com CD44 (clone IM7) como controle positivo.

Em relação ao anticorpo CD24, pode se observar maior número de células marcadas em neoplasias grau I (Fig. 2). Já nos tumores graus II e III notaram-se poucas ou raras imunomarcações em células neoplásicas. 0 controle positivo utilizado foi tecido parafinizado de tonsila humana, sendo a imunomarcação em membrana plasmática e em citoplasma.

Para o anticorpo Oct-4 notou-se que as imunomarcações foram nucleares (Fig. 3), comprovadas em seus controles positivos internos, o bulbo do folículo piloso. Em relação à intensidade, nos CTMs observou-se imunomarcação extremamente forte em células epiteliais mamárias bem diferenciadas. Em células menos diferenciadas a intensidade de imunomarcação foi diminuída, ou seja, em células histologicamente mais indiferenciadas, a imunomarcação se tornava mais fraca ou ausente. Já nos CSs o número de células imunomarcadas foi expressivo tanto nas porções mesenquimais quanto epiteliais.

Não foi observada imunomarcação com o anticorpo

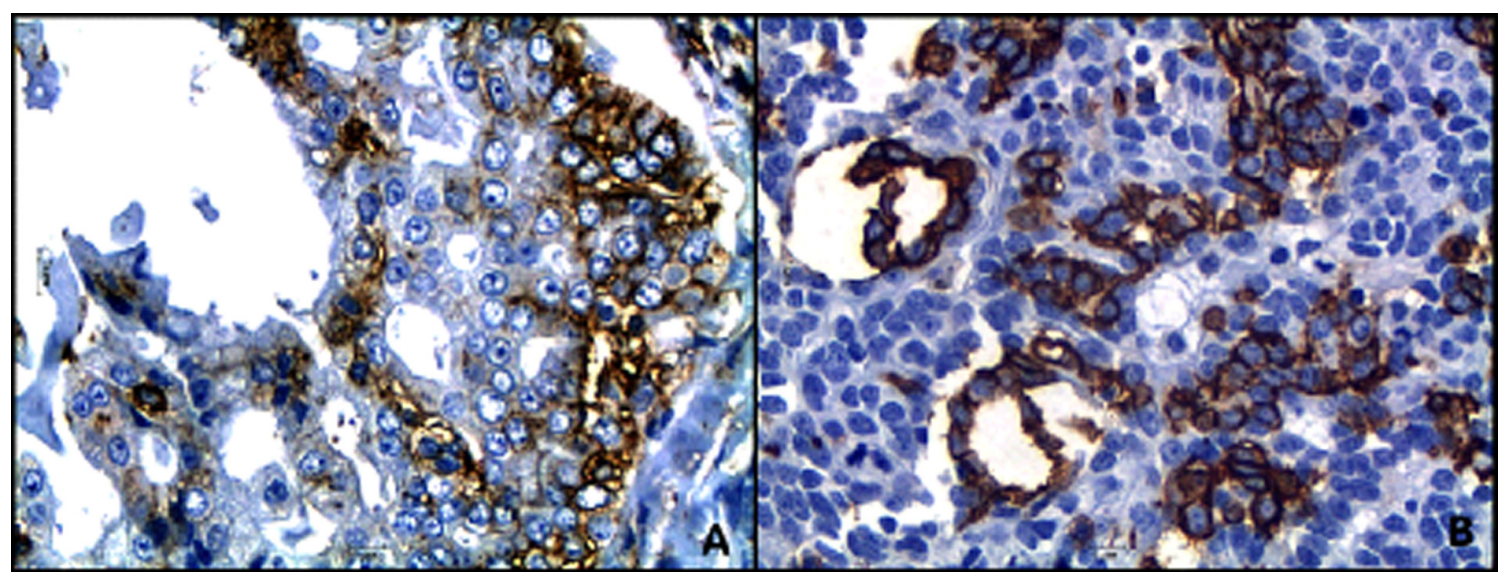

Fig.1. (A) CTM grau I em cadela. (B) CTM grau II cadela. Notar marcação imuno-histoquímica para CD44, observada na membrana plasmática das células epiteliais neoplásicas. DAB e contra-coloração com Hematoxilina de Harris, obj.40x.

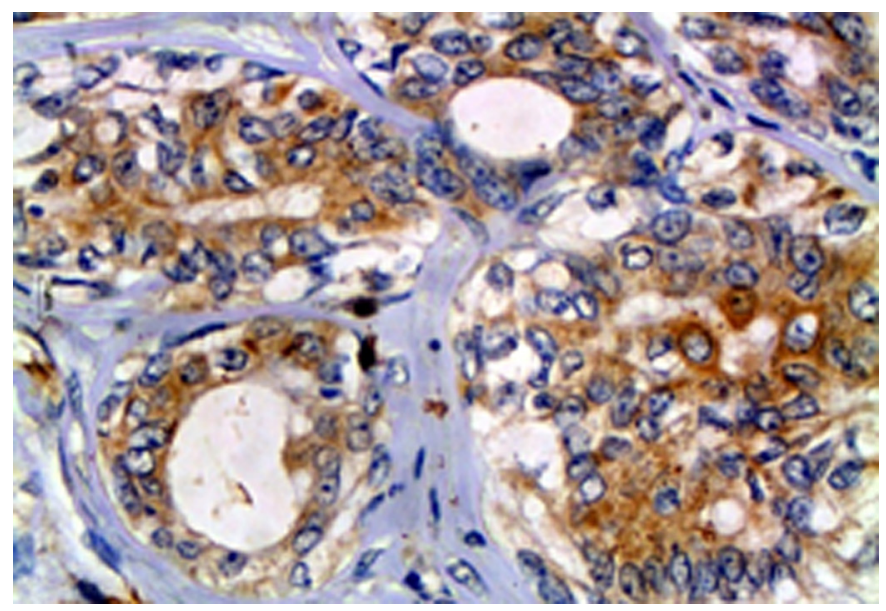

Fig.2. Carcinoma em tumor misto grau I em cadela. Notar marcação imuno-histoquímica para CD24, observada na membrana plasmática e citoplasma das células epiteliais neoplásicas. DAB e contra-coloração com Hematoxilina de Harris, obj.40x.

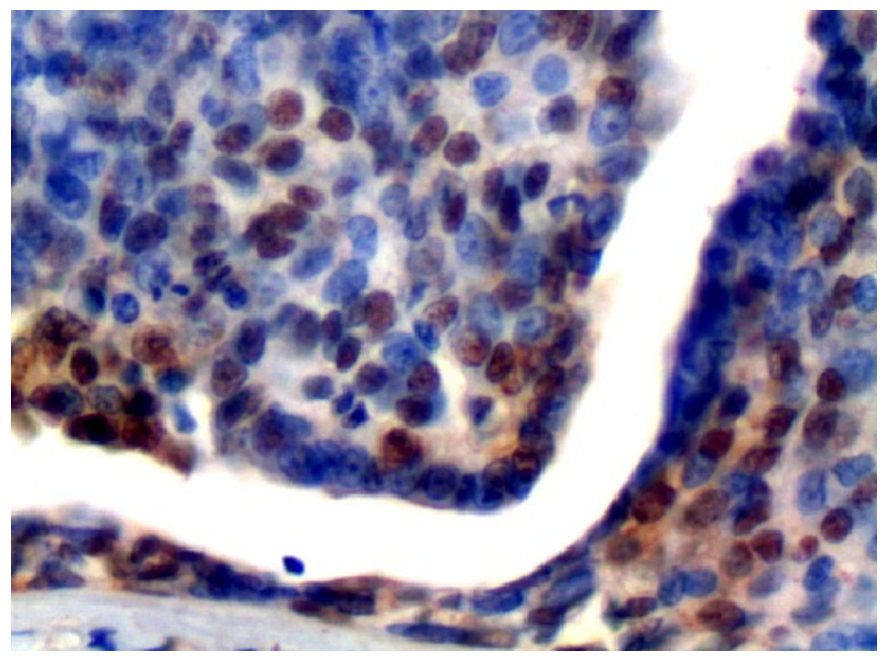

Fig.3. Neoplasia mamária canina. Notar marcação imuno-histoquímica em núcleos de células epiteliais em para Oct-4. DAB e contra-coloração com Hematoxilina de Harris, obj.40x. 
ALDH-1 na maioria dos tipos histológicos, e quando presente não ultrapassou $10 \%$ das células imunomarcadas. Essas marcações ocorreram nas membranas plasmáticas e no citoplasma e ambos estavam intensamente corados (Fig. 4). Alguns ductos mamários normais (Fig. 5) localizados em alguns neoplasmas foram imunomarcados para este anticorpo.

Para o CS, as comparações entre as porções epiteliais e mesenquimais dos anticorpos CD44 (Fig. 6A e B) CD24, Oct-4 e ALDH-1 não apresentaram diferenças significativas pelo teste Mann Whitney. Os valores das porções epiteliais e mesenquimais para esses respectivos anticorpos estão representados no Quadro 2. No CD44 o valor de $p=0,6991$; CD24 com $\mathrm{p}=0,2354$; Oct- $4, \mathrm{p}=0,8090$ e no ALDH-1 $\mathrm{p}=$ 0,2328, (Fig.7A-D).

Nos CTMs as imunomarcações para os anticorpos CD44, CD24 e Oct-4 ocorreram apenas em células epiteliais. 0 anticorpo ALDH-1 marcou poucas ou raras células epiteliais nos carcinomas em tumores mistos mamários grau I. Nos graus II e III não foram observadas imunomarcações (Quadro 3). Nas comparações das porções epiteliais não foram observadas diferenças estatísticas entre os anticorpos CD44, CD24 e Oct-4 (Fig.8).

\section{DISCUSSÃO}

O tumor de mama é uma das neoplasias mais frequentemente diagnosticadas na rotina médico veterinária. Dentre estes, o CTM é um dos tipos histológicos mais comuns. Esses tumores exibem um padrão complexo histológico que consiste de porção epitelial (maligna) e mesenquimal bem diferenciada (Cassali et al. 2011). Neste trabalho observaram-se imunomarcações nas porções epiteliais para os anticorpos CD44, CD24 e Oct-4, sem diferenças significativas entre os graus (I, II e III). A homogeneidade de imunomarcação sugere semelhança entre o grau de diferenciação celular. Autores encontraram predomínio de características de baixo grau de malignidade nos carcinomas em tumores mistos e relacionaram a origem desses neoplasmas com

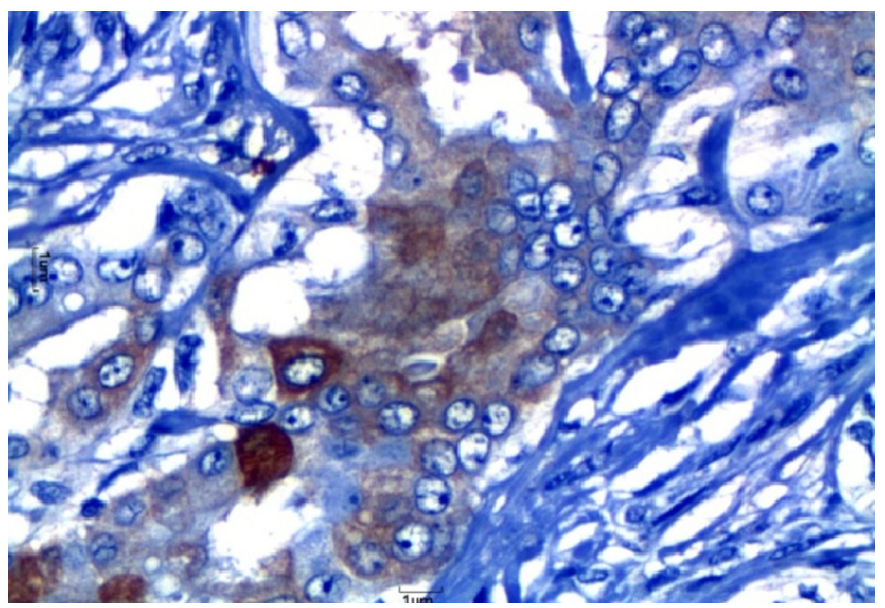

Fig.4. Carcinoma em tumor misto grau I em cadela. Notar marcação imuno-histoquímica para ALDH-1 em citoplasma de células epiteliais. DAB e contra-coloração com Hematoxilina de Harris, obj.40x.

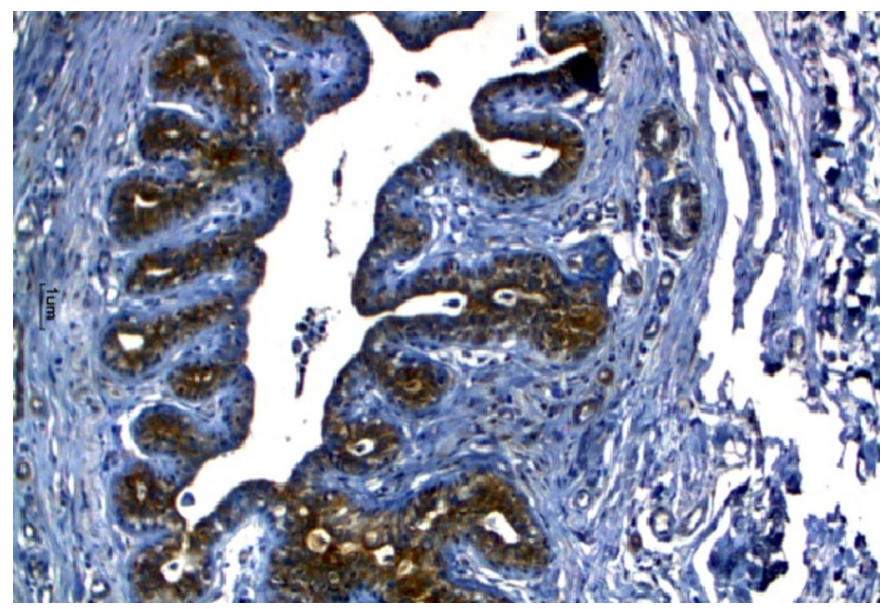

Fig.5. Ducto mamário em cadela. Notar marcação imuno-histoquímica para ALDH-1 em citoplasmas de células epiteliais. DAB e contra-coloração com Hematoxilina de Harris, obj.40x.

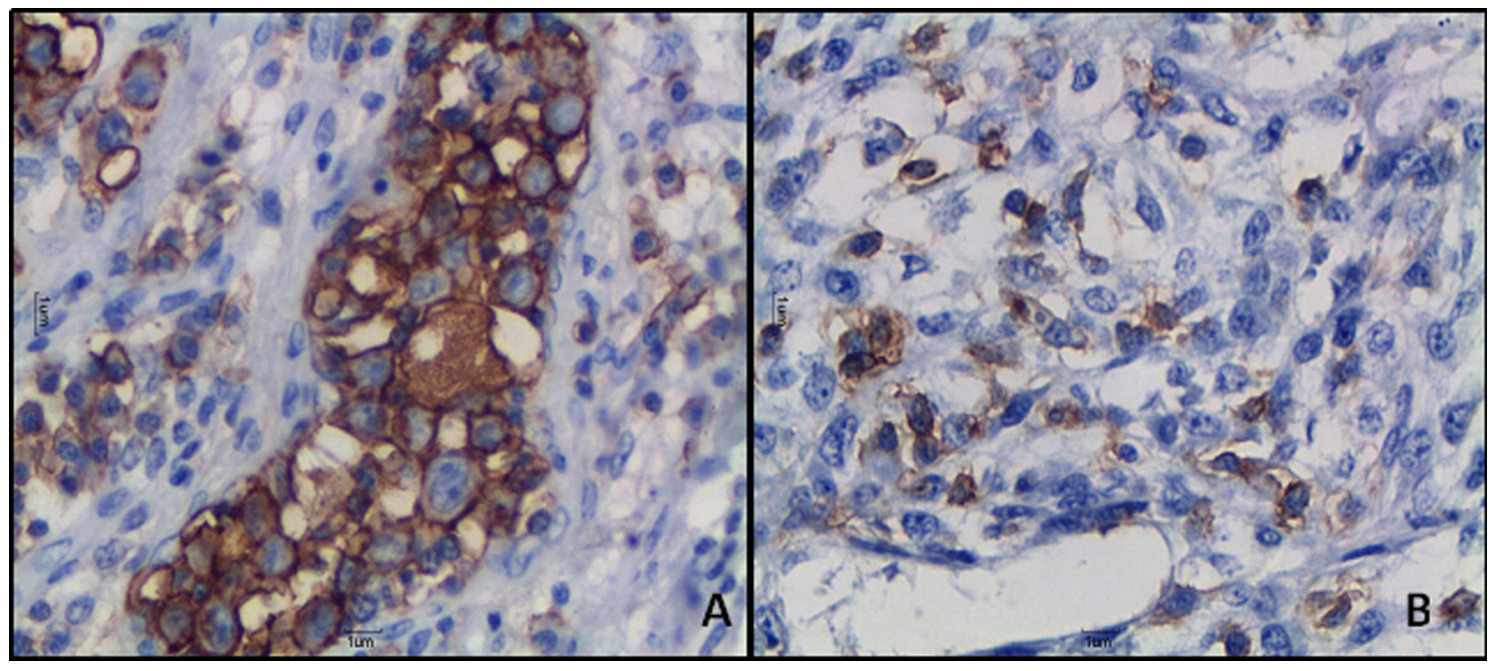

Fig.6. Carcinossarcoma mamário em cadela. (A) Notar marcação imuno-histoquímica para CD44, observada na membrana plasmática e citoplasma das células epiteliais e (B) mesenquimais neoplásicas. DAB e contra-coloração com Hematoxilina de Harris. Obj. 40x 
Quadro 2. Porcentagem de células epiteliais e mesenquimais neoplásicas de carcinossarcomas mamários caninos imunomarcadas para CD44, CD24, 0ct-4 e ALDH-1

\begin{tabular}{ccccccccc}
\hline Animal & \multicolumn{1}{c}{ CD44 } & \multicolumn{2}{c}{ CD24 } & \multicolumn{2}{c}{ Oct-4 } & ALDH-1 \\
\hline & $\mathrm{E}^{*}$ & $\mathrm{M}^{*}$ & $\mathrm{E}$ & $\mathrm{M}$ & $\mathrm{E}$ & $\mathrm{M}$ & $\mathrm{E}$ & $\mathrm{M}$ \\
1 & 60 & 70 & 30 & 30 & 90 & 90 & 0 & 0 \\
2 & 77 & 27 & 10 & 0 & 60 & 30 & 5 & 0 \\
3 & 50 & 80 & 30 & 30 & 30 & 50 & 7 & 0 \\
4 & 50 & 30 & 30 & 0 & 70 & 70 & 40 & 0 \\
5 & 30 & 30 & 0 & 0 & 50 & 50 & 0 & 0 \\
6 & 33 & 50 & 0 & 0 & 80 & 80 & 0 & 0 \\
Médias & 50 & 47,8 & 16,6 & 10 & 63,3 & 61,6 & 8,6 & 0
\end{tabular}

${ }^{*} \mathrm{E}=$ células epiteliais neoplásicas, $\mathrm{M}$ = células mesenquimais neoplásicas.

A

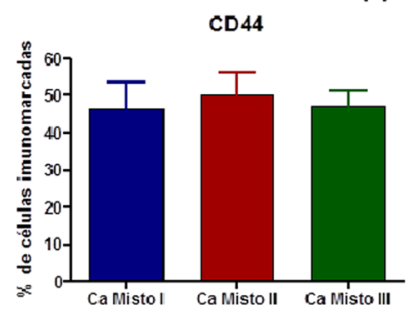

B

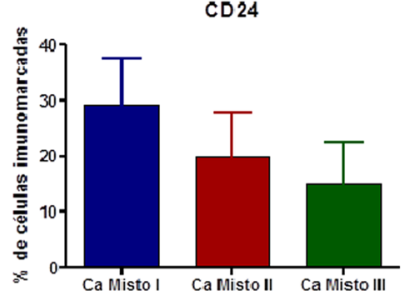

OCT

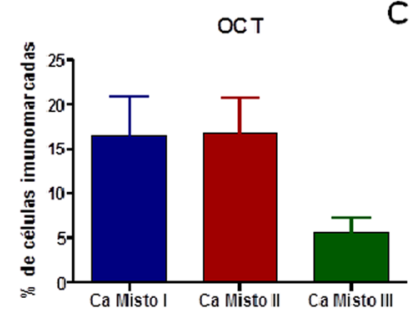

Fig.7. Porcentagem de imunomarcação para os anticorpos CD44 (A), CD24 (B), Oct-4 (C) e ALDH-1 (D) nos componentes epiteliais e mesenquimais de carcinossarcomas mamários caninos. Ausência de diferença estatística pelo teste de comparação múltipla de Dunn.

Quadro 3. Médias percentuais e erro-padrão das médias das células imunomarcadas pelo teste de Kruskal-Wallis nos carcinomas em tumores mistos mamários graus I, II e III

\begin{tabular}{lcccc}
\hline Grupos & CD44 & CD24 & Oct-4 & ALDH-1 \\
\hline Misto1 & $46,3 \pm 7,2$ & $29,2 \pm 8,1$ & $16,5 \pm 4,3$ & $1,4 \pm 2,3$ \\
Misto2 & $50,1 \pm 5,9$ & $20,0 \pm 7,6$ & $16,8 \pm 3,9$ & $0 \pm 0$ \\
Misto3 & $47,2 \pm 3,9$ & $15,0 \pm 7,3$ & $5,7 \pm 1,5$ & $0 \pm 0$
\end{tabular}

mais de um tipo celular (luminal e mioepitelial) (Ribeiro et al. 2012). Não se sabe exatamente se a origem celular contribui para a heterogeneidade do câncer de mama em mulheres e ainda qual tipo celular seria o mais susceptível a oncogênese (Polyak 2007). Por outro lado, foi comprovado que tanto os componentes epiteliais quanto as células mioepiteliais apresentam o mesmo DNA, sugerindo a possibilidade de ambos os componentes serem originados de uma célula-tronco totipotente (Gärtner et al., 1999). Em células epiteliais neoplásicas mamárias humanas sabe-se que ocorrem imunomarcações para CTTs variando entre $2 \%$ e $40 \%$, e ainda que estas marcações foram fortemente ligadas ao grau histopatológico e à agressividade tumoral
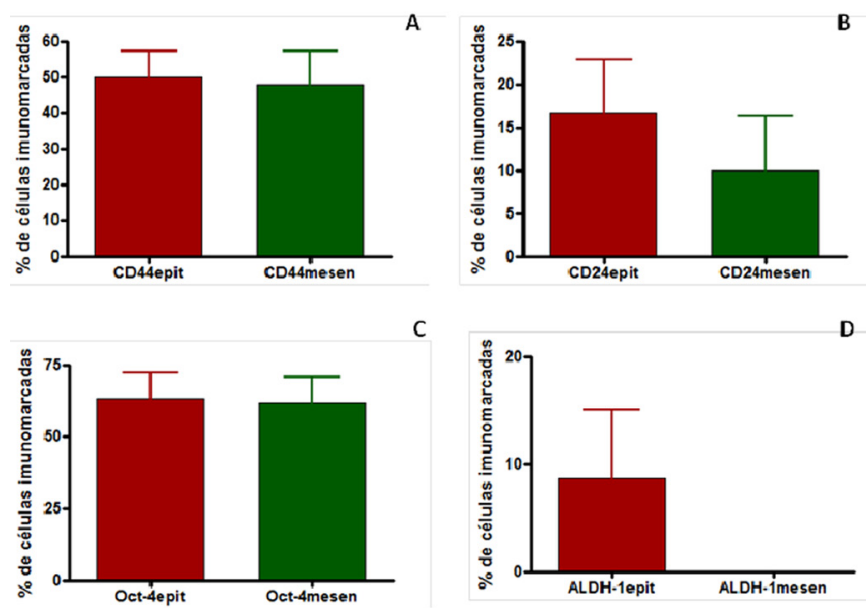

Fig.8. Porcentagem de imunomarcação para o anticorpo CD44 (A), CD24 (B) e Oct-4 (C) nos carcinomas em tumores mistos grau I, II e III de cães. Ausência de diferença estatística pelo teste de comparação múltipla de Dunn.

(Lorico et al. 2011). Autores encontraram variações nas imunomarcações de Oct-4 em 83 tumores caninos A variação foi desde menos de $1 \%$ até mais de $90 \%$ das células neoplásicas positivas para esse marcador (Webster et al. 2007). Em estudos com neoplasias mamárias caninas esta mesma relação foi observada, com células epiteliais imunomarcadas em neoplasmas mais agressivos (Magalhães et al. 2013).

Em relação à origem celular mesenquimal, neste trabalho somente os CSs imunomarcaram para as CTTs, com exceção do marcador ALDH-1. Em outros tumores mesenquimais, como fibrossarcoma (Liu et al. 2012) e leiomioma (Mas et al. 2012), autores identificaram a presença de CTTs. Em estudo com carcinoma gástrico observou-se que as CTTs mesenquimais realizam mediação das ativações das vias do gene $W N T$ e do TGF- $\beta$ (fator transformador do crescimento $\beta$ ), proporcionando um microambiente vantajoso para a requisição e manutenção das células-tronco tumorais (Nishimura et al. 2012). Em neoplasmas do sistema nervoso, especificamente nos gliomas, as CTTs estão localizadas em nichos, ou microambientes especializados dentro do tumor e são responsáveis pela progressão tumoral (Filatova et al. 2013).

Nas células mesenquimais neoplásicas apenas o anticorpo ALDH-1 não foi positivo nos CSs. Autores relacionaram a expressão de ALDH-1 com neoplasias mamárias humanas de alto grau, mas não estabeleceram essa molécula como um importante fator prognóstico e de metástase (Ginestier et al. 2007). Em relação aos CTMs, pouca quantidade de ALDH-1 foi encontrada apenas no grau I, não estando relacionada com a agressividade. Em Medicina Veterinária, autores demonstraram em linhagens celulares derivadas de neoplasmas mamários caninos com capacidade de autorrenovação (CD44+/CD24-), altos níveis de ALDH-1 (Michishita et al. 2012), verificado por citometria de fluxo. Em mulheres, a técnica de imuno-histoquímica foi fidedigna para a marcação de ALDH-1 em neoplasias mamárias em blocos parafinados (Ginestier et al. 2007), portanto, novos estudos para esse marcador de CTTs de- 
vem ser realizados em neoplasias mamárias caninas. Em relação ao CS, esse estudo não apresentou diferenças significativas quando comparados os anticorpos CD44, CD24, Oct-4 e ALDH-1, nas porções epiteliais e mesenquimais. Porém, pode-se observar que as marcações tanto no epitélio como no mesênquima adquiriram um padrão mais elevado para os anticorpos CD44 e Oct-4, e mais baixo para o CD24 e ALDH-1.

Através dos resultados apresentados no Quadro 2 é possível observar uma grande amplitude na marcação entre as porções epiteliais e mesenquimais destes tumores e mesmo dentro destas porções. Uma possível explicação para este fato pode ser a diferença de agressividade entre as porções epitelial e mesenquimal destes tumores, inclusive dentro de um mesmo tumor, como já referido por outros autores; a metástase pode ocorrer a partir da porção epitelial, mesenquimal ou de ambas (Cassali et al. 2011). Há observações que sugerem fortemente que os CSs mamários humanos são derivados de uma única célula-tronco totipotente (Wada et al., 1998), que daria origem às células malignas tanto da porção epitelial quanto da mesenquimal presentes neste neoplasma. Ainda, nos CSs humanos autores sugeriram que as porções epiteliais e mesenquimais são ambas componentes do parênquima do neoplasma e também concordam com a hipótese da origem monoclonal (Teixeira et al., 1998). Em Medicina Veterinária não há informações sobre a origem dos CSs, mas em nosso estudo ambos os componentes epiteliais e mesenquimais apresentaram o mesmo padrão de marcação para as CTTs, sugerindo igual agressividade dessas porções.

\section{CONCLUSÕES}

A detecção das CTTs através dos anticorpos CD44, CD24, Oct-4 e ALDH-1 pode ser realizada em neoplasmas mamários caninos, assim como nos neoplasmas mamários humanos. Este fato pode viabilizar novas pesquisas nesta área na Medicina Veterinária, bem como facilitar a aplicação dos resultados devido à facilidade do método empregado, a imuno-histoquímica.

As porções epiteliais e mesenquimais dos CSs apresentam semelhanças nas imunomarcações para CTTs, sugerindo igual agressividade dessas porções, bem como uma origem monoclonal para esta neoplasia. A porção mesenquimal dos CTMs não apresentou marcação pelas CTTs, provavelmente por serem células bem diferenciadas, o que confirma o comportamento benigno desta porção do neoplasma. As células epiteliais dos CTMs não diferiram significativamente quanto à imunomarcação para CTTs, provavelmente por serem neoplasias que não apresentam características de elevada malignidade.

\section{REFERÊNCIAS}

Al-Hajj M. \& Clarke M.F. 2004. Self-renewal and solid tumor stem cells. Oncogene 23(43):7274-7282.

Al-Hajj M., Wicha M.S., Benito-Hernandez A., Morrison S.J. \& Clarke M.F. 2003. Prospective identification of tumorigenic breast cancer cells. Proc. Natl Acad. Sci. USA 100(7):3983-3988.

Blacking T.M., Wilson H. \& Argyle J. 2007. Is cancer a stem cell disease? Theory, evidence and implications. Vet. Comp. Oncol. 5(2):76-89.
Cassali G.D., Lavalle G.E., De Nardi A.B., Ferreira E., Bertagnolli A.C., Estrela-Lima A., Alessi A.C., Daleck C.R., Salgado B.S., Fernandes C.G., Sobral R.A., Amorim R.L., Gamba C.O., Damasceno K.A., Auler P.A., Magalhães G.M., Silva J.O., Raposo J.B., Ferreira A.M.R., Oliveira L.O., Malm C., Zuccari D.A.P.C., Tanaka N.M., Ribeiro L.R., Campos L.C., Souza C.M., Leite J.S., Soares L.M.C., Cavalcanti M.F., Fonteles Z.G.C., Schuch I.D., Paniago J., Oliveira T.S., Terra E.M., Castanheira T.L.L., Felix A.O.C., Carvalho G.D., Guim T.N., Guim T., Garrido E., Fernandes S.C., Maia F.C.L., Dagli M.L.Z., Rocha N.S., Fukumasu H., Grandi F., Machado J.P., Silva S.M.M.S., Bezerril J.E., Frehse M.S., Paes de Almeida E.C. \& Campos C.B. 2011. Consensus for the diagnosis, prognosis and treatment of canine mammary tumors. Braz. J. Vet. Pathol. 4(2):153-180.

Clarke M.F., Dick J.E., Dirks P.B., Eaves C.J., Jamieson C.H.M., Jones D.L., Visvader J., Weissman I.L. \& Wahl G.M. 2006. Cancer stem cells- perspectives on current status and future directions: AACR Workshop on cancer stem cells. Cancer Res. 66(19):9339-9344.

De Nardi A.B., Rodaski S., Sousa R.S., Costa T.A., Macedo T.R., Rodigheri S.M., Rios A. \& Piekarz C.H. 2002. Prevalence of neoplasias and kind of treatments in dogs seen in Veterinary Hospital at University Federal of Paraná. Archs Vet. Sci. 7(2):15-26.

Ferletta M., Grawé J. \& Hellmén E. 2011. Canine mammary tumors contain cancer stem-like cells and form spheroids with an embryonic stem cell signature. Int. J. Develop. Biol. 55:791-799.

Filatova A., Acker T. \& Garvalov B.K. 2013. The cancer stem cell niche(s): the crosstalk between glioma stem cells and their microenvironment. Biochim. Biophys. Acta 1830:2496-2508.

Gärtner F., Geraldes M., Cassali G., Rema A., Schmitt F. 1999. DNA measurement and immunohistochemical characterization of epithelial and mesenchymal cells in canine mixed mammary tumours: putative evidence for a common histogenesis. Vet. J. 158(1):39-47.

Ginestier C., Hur M.H., Charafe-Jauffret E., Monville F., Dutcher J., Brown M., Jacquemier J., Viens P., Kleer C., Liu S., Schott A., Hayes D., Birnbaum D., Wicha M.S. \& Dontu G. 2007. ALDH1 is a marker of normal and malignant human mammary stem cells and a predictor of poor clinical outcome. Cell Stem Cell 11(5):555-567.

Kunju L.P., Toy K., Thomas D., Ding Y. \& Kleer C.G. 2011. Expression of the stem cell markers ALDH1 and EZH2 in triple negative invasive breast carcinomas. Lab. Invest. 89(1):52.

Liu W.D., Zhang T., Wang C.L., Meng H.M., Song Y.W., Zhao Z., Li Z.M., Liu J.K., Pan S.H. \& Wang W.B. 2012. Sphere-forming tumor cells possess stemlike properties in human fibrosarcoma primary tumors and cell lines. Oncology Letters 4(6):1315-1320.

Lorico A. \& Rappa G. 2011. Phenotypic heterogeneity of breast cancer stem cells. J. Oncology 18(1):1-6.

Mas A., Cervelló I., Gil-Sanchis C., Faus A., Ferro J., Pellicer A. \& Simón C. 2012. Identification and characterization of the human leiomyoma side population as putative tumor-initiating cell. Fertility and Sterility 98(3):741-751.

Magalhães G.M., Terra E.M., Vasconcelos R.O., Bandarra M.B., Moreira P.R.R., Rosolem M.C.\& Alessi A.C. 2013. Immunodetection of cells with a CD44+/CD24- phenotype in canine mammary neoplasms. BMC Vet. Res. 9:205.

Michishita M., Akiyoshi R., Yoshimura H., Katsumoto T., Ichikawa H., Ohkusu-Tsukada K., Nakagawa T., Sasaki N. \& Takahashi K. 2011. Characterization of spheres derived from canine mammary gland adenocarcinoma cell lines. Res. Vet. Sci. 91:254-260.

Michishita M., Akiyoshi R., Suemizu H., Nakagawa T., Sasaki N., Takemitsu H., Arai T. \& Takahashi K. 2012. Aldehyde dehydrogenase activity in cancer stem cells from canine mammary carcinoma cell lines. Vet. Journal. 193(2):508-513.

Misdorp W., Cotchin E., Hampe J.F., Jabara A.G. \& Von Sandersleben J. 1973. Canine malignant mammary tumors III. Special types of carcinomas, malignant mixed tumors. Vet. Pathol. 10:241-256.

Nishimura K., Semba S., Aoyagi K., Sasaki H. \& Yokozaki H. 2012. Mesenchymal stem cells provide an advantageous tumor microenvironment for the restoration of cancer stem cells. Pathobiology 79(6):290-306.

Oliveira Filho J.C., Kommers G.D., Masuda E.K., Marques B.M.F.P.P., Fighera 
R.A., Irigoyen L.F. \& Barros C.S.L. 2010. Estudo retrospectivo de 1.647 tumores mamários em cães. Pesq. Vet. Bras. 30(2):177-185.

Pang L.Y. \& Argyle D.J. 2010 Using naturally occurring tumours in dogs and cats to study telomerase and cancer stem cell biology. Biochimica et Biophysica Acta 1792:380-391.

Ponti D., Costa A., Zaffaroni N., Pratesi G., Petrangolini G., Coradini D., Pilotti S., Pierotti M.A. \& Daidone M. 2005. Isolation and in vitro propagation of tumorigenic breast cancer cells with stem/progenitor cell properties. Cancer Res. 65(13):5506-5511.

Polyak K. 2007. Breast cancer: origins and evolution. J. Clin. Invest. 117: 3155-3163.

Ribeiro G.M., Bertagnolli A.C., Rocha R.M., Cassali G.D. 2012. Morphological aspects and imunophenotypic profiles of mammary carcinomas in benign mixed tumors of female dogs. Vet. Med. Int. 2012:1-7.
Teixeira M.R., Qvist H., Bohler P.J., Pandis N. \& Heim S. 1998. Cytogenetic Analysis Shows That Carcinosarcomas of the Breast Are of Monoclonal Origin. Genes, Chromosomes and Cancer 22(2):145-151.

Wada H., Enomoto T., Tsujimoto M., Nomura T., Murata Y., Shroyer K.R. 1998. Carcinosarcoma of the breast: molecular-biological study for analysis of histogenesis. Human Pathol. 29(11):1324-1328.

Webster J.D., Yuzbasiyan-Gurkan V., Trosko J.E., Chang C.-C., Kiupel M. 2007. Expression of the embryonic transcription factor Oct4 in canine neoplasms: a potential marker for stem cell subpopulations in neoplasia. Vet. Pathol. 44:893-900.

Widakowich C., Azambuja E., Gil T., Cardoso F., Dinh P., Awada A. \& PiccartGebhart M. 2007. Molecular targeted therapies in breast cancer: Where are we now? Int. J. Biochem. Cell Biol. 39:1375-1387. 